\title{
Phosphorylated Histone H2AX
}

National Cancer Institute

\section{Source}

National Cancer Institute. Phosphorylated Histone H2AX. NCI Thesaurus. Code C129645.

A post-translationally modified form of variant histone $\mathrm{H} 2 \mathrm{AX}$ where the serine residue at position 139 and/or the tyrosine residue at 142 is phosphorylated. Phosphorylation of serine-139 may be a marker for DNA damage. While phosphorylation or dephosphorylation of tyrosine-142 appears to affect the recruitment of pro-apoptotic factors or DNA repair proteins, respectively. 